\title{
Prognostic analysis of patients with non- small cell lung cancer harboring exon 19 or 21 mutation in the epidermal growth factor gene and brain metastases
}

Jing Wang ${ }^{\dagger}$, Zhiyan Liư ${ }^{\dagger}$ Qingsong Pang, Tian Zhang, Xi Chen, Puchun Er, Yuwen Wang, Ping Wang ${ }^{*}$ and Jun Wang*

\begin{abstract}
Background: In 1997, the Radiation Therapy Oncology Group (RTOG) put forward the recursive partitioning analysis classification for the prognosis of brain metastases (BMs), but this system does not take into account the epidermal growth factor receptor (EGFR) mutations. The aim of the study is to assess the prognosis of patients with EGFRmutated non-small cell lung cancer (NSCLC) and BMs in the era of tyrosine kinase inhibitor (TKI) availability.

Methods: This was a retrospective study of consecutive patients with EGFR-mutated (exon 19 or 21) NSCLC diagnosed between 01/2011 and 12/2014 at the Tianjin Medical University Cancer Institute \& Hospital and who were ultimately diagnosed with BMs. The patients were stage I-III at initial presentation and developed BMs as the first progression. Overall survival (OS), OS after BM diagnosis (mOS), intracranial progression-free survival (iPFS), response to treatment, and adverse reactions were analyzed.

Results: Median survival was 35 months, and the 1- and 2-year survival rates were 95.6\% (108/113) and 74.3\% (84/ 113). The 3-month $C R+P R$ rates of radiotherapy $(R)$, chemotherapy $(C)$, targeted treatment $(T)$, and targeted treatment + radiotherapy $(T+R)$ after BMs were 63.0\% (17/27), 26.7\% (4/15), 50.0\% (7/14), and 89.7\% (35/39), respectively. The median survival of the four treatments was $20,9,12$, and 25 months after BMs, respectively $(P=0.001)$. Multivariable analysis showed that $<3$ BMs (odds ratio $(\mathrm{OR})=3.34,95 \%$ confidence interval $(C \mathrm{Cl}): 1.89-5.91, P<0.001$ ) and treatment after $\mathrm{BMs}(\mathrm{OR}=0.68,95 \% \mathrm{Cl}: 0.54-0.85, P=0.001)$ were independently associated with better prognosis.

Conclusions: The prognosis of patients with NSCLC and EGFR mutation in exon 19 or 21 after BM is associated with the number of brain metastasis and the treatment method. Targeted treatment combined with radiotherapy may have some advantages over other treatments, but further study is warranted to validate the results.
\end{abstract}

Keywords: Non-small cell lung cancer, Brain metastasis, epidermal growth factor receptor mutation, Prognosis, Treatment

\footnotetext{
* Correspondence: wangping@tjmuch.com; wangjing@tjmuch.com

${ }^{\dagger}$ Jing Wang and Zhiyan Liu contributed equally to this work.

Department of Radiation Oncology, Tianjin Medical University Cancer

Institute and Hospital, Key Laboratory of Cancer Prevention and Therapy,

National Clinical Research Center for Cance, Tianjin's Clinical Research Centre

for Cancer, Huan-Hu-Xi Road, Ti-Yuan-Bei, He Xi District, Tianjin 300060, PR

China
}

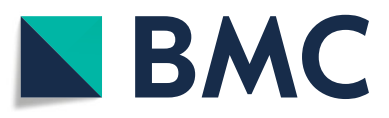

( The Author(s). 2020 Open Access This article is licensed under a Creative Commons Attribution 4.0 International License, which permits use, sharing, adaptation, distribution and reproduction in any medium or format, as long as you give appropriate credit to the original author(s) and the source, provide a link to the Creative Commons licence, and indicate if changes were made. The images or other third party material in this article are included in the article's Creative Commons licence, unless indicated otherwise in a credit line to the material. If material is not included in the article's Creative Commons licence and your intended use is not permitted by statutory regulation or exceeds the permitted use, you will need to obtain permission directly from the copyright holder. To view a copy of this licence, visit http://creativecommons.org/licenses/by/4.0/. The Creative Commons Public Domain Dedication waiver (http://creativecommons.org/publicdomain/zero/1.0/) applies to the data made available in this article, unless otherwise stated in a credit line to the data. 


\section{Background}

Lung cancer is the cancer with the world's highest morbidity and mortality [1]. Non-small cell lung cancer (NSCLC) accounts for $80-85 \%$ of the cases of lung cancer. NSCLC mainly affects adults $>65$ years old, tobacco smokers, and men [2, 3]. In China, in 2014, approximately 2,114,000 men and 1,690,000 women have been diagnosed with lung cancer, representing 10,422 new cases each day; in addition, there were 2,296,000 deaths attributable to lung cancer in 2014 [4].

Mutation in the epidermal growth factor receptor $(E G F R)$ gene is now a key target in the treatment of NSCLC. Indeed, afatinib, erlotinib, gefitinib, icotinib, and osimertinib have been shown to improve the prognosis and survival of patients harboring EGFR sensitizing mutations $[2,5]$.

Brain metastases (BMs) are the main form of distant metastases in lung cancer and is one of the main causes of treatment failure [2, 3]. Approximately 25\% of patients with NSCLC suffer from BM, and its occurrence influences survival [2, 3]. As early as 1997, the Radiation Therapy Oncology Group (RTOG) put forward a recursive partitioning analysis (RPA) for the classification of BMs [6], which was the first prognostic scoring system for assessing the prognosis of patients with BM, but this system does not take into account the presence of EGFR mutations. The therapeutic modalities to control BMs include whole-brain radiotherapy (WBRT), stereotactic radiosurgery (SRS), surgery, and chemotherapy, and the best approach has to be tailored to each patient based on the number of lesions, their size, their exact location, and the extent of invasion [2,3]. Furthermore, the optimal treatment is unknown for EGFR-mutated patients with NSCLC and BMs [7], and this important research question remains to be examined.

Therefore, the aim of the present study was to assess the prognosis of patients with EGFR-mutated NSCLC and BMs in the era of TKI availability (except osimertinib, which was not available during the study period).

\section{Methods}

\section{Study design and patients}

This was a retrospective study of the consecutive patients with stage I-III NSCLC diagnosed between January 2011 and December 2014 at the Tianjin Medical University Cancer Institute \& Hospital and who were ultimately diagnosed with BMs. The study was carried out in accordance with the Declaration of Helsinki and was approved by the ethics committee of Tianjin Medical University Cancer Institute \& Hospital. The need for individual consent was waived by the committee.

The inclusion criteria were: 1) stage I-III NSCLC at initial diagnosis; 2) eligible to surgery and underwent radical surgery; 3 ) diagnosis confirmed by postoperative pathological examination; 4) confirmed with exon 19 deletion and exon 21 L858R missense mutation of EGFR using the surgical specimen after radical surgery; 5) did not have BMs before or after radical surgery; and 6) developed BMs during routine follow-up as the first progression. The patients with meningeal metastases were excluded.

\section{Treatments}

All patients accepted standard lung cancer radical surgeries and adjuvant treatment according to the current guidelines at the time of their initial diagnosis. The diagnosis of BM was made based on enhanced head magnetic resonance (MRI) results. All patients had at least one measurable lesion (excluding patients with meningeal metastases).

The treatment options for BMs were: chemotherapy, radiotherapy, targeted therapy, and targeted therapy combined with radiotherapy. For radiotherapy, WBRT (40 Gy in 20 fractions or 30 Gy in 10 fractions) and/or SRS were conducted. For targeted therapy, gefitinib (250 $\mathrm{mg}$, oral, once/day), erlotinib (150 mg, oral, once/day), or icotinib (125 mg, oral, three times/day) was used. The treatments were conducted until disease progression, death, or intolerable adverse reactions. The treatment selection was performed by a discussion between the patient and the physician. All cases were discussed at tumor boards. Some patients refused treatments because of costs since TKIs were expensive and not reimbursed by all insurance providers in China during the study period.

\section{Evaluation criteria}

Overall survival (OS) was defined as the time from disease diagnosis to death or last follow-up. Overall survival after BM diagnosis (mOS) was the time from the diagnosis of BM to death or last follow-up. We defined intracranial progression-free survival (iPFS) as the interval between the diagnosis of BM and intracranial progression or mortality from any cause $[8,9]$. The therapeutic effects were evaluated at 3 months using the RECIST criteria [10]. The therapeutic effect was classified as complete response (CR), partial response (PR), stable disease (SD), and progressive disease (PD). The objective response rate (ORR) was $C R+P R$. Toxicity was routinely documented according to the Common Terminology Criteria for Adverse Events (CTCAE) 3.0 [11].

\section{Data collection}

All data were collected from the medical charts. The baseline characteristics were those at the time of BM diagnosis. The symptoms of BMs included dizziness, headache, nausea, vomiting, restricted limb activities, and unsteady walking. 


\section{Statistical analysis}

The continuous data were tested with the KolmogorovSmirnov test for normal distribution. Normally distributed continuous data are described as means \pm standard deviation and were analyzed using the Student t-test or ANOVA with Tukey's post hoc test, as appropriate. Skewed continuous variables are presented as median (range) and were analyzed using the Mann-Whitney U test or the Kruskal-Wallis test, as appropriate. The categorical variables are presented as frequencies and percentages and were analyzed using the chi-square test. The curves for OS, iPFS, and mOS were plotted using the Kaplan-Meier method, and comparisons between groups were calculated using the log-rank test. Multivariable analysis was carried out using Cox proportional hazard models (enter method) using variables that were significant in univariable analyses. $P$ values $<0.05$ were considered statistically significant. SPSS 18.0 for Windows (IBM, Armonk, NY, USA) was used for statistical analysis.

\section{Results}

\section{Patient characteristics}

From 560 patients with NSCLC who underwent radical resection and EGFR mutation testing, 113 (20.2\%) with exon 19 deletion and exon 21 L858R missense mutation of EGFR and developed BMs as the first progression were included in this study. All cases were adenocarcinomas. Their median follow-up time was 30 months. Of the included cases, 44/113 cases were male (38.9\%), and $69 / 113$ cases were female $(61.1 \%)$. The median age at onset was 58 (range, 31-79) years, with 91/113 (80.5\%) patients being 65 years of age or younger, and 42/113 (37.2\%) were smokers. Thirty patients received WBRT, 63 patients received stereotactic ablative radiotherapy (SABR), and 20 patients received a combination of WBRT and SABR. Regarding mutations, there were 52/ $113(46.0 \%)$ cases of mutation in exon 19 and 61/113 (54.0\%) of mutation in exon 21 . The numbers of patients with stage I, II, and III NSCLC were 50/113 (44.2\%), 11/ $113(9.7 \%)$, and 52/113 (46.0\%), respectively.
After being confirmed with BMs, 95/113 (84.1\%) patients received further treatments: chemotherapy for $15 /$ 95 patients $(15.8 \%)$, radiotherapy for $27 / 95$ (28.4\%), targeted therapy for $14 / 95$ (14.7\%), and targeted therapy combined with radiotherapy for 39/95 (41.1\%).

\section{Treatment response}

The proportion of patients with a complete or partial response after BM was significantly different across the treatment groups $(P<0.05)$ (Table 1$)$. The proportion of $\mathrm{CR}+\mathrm{PR}$ was $63.0 \%(17 / 27)$ for radiotherapy, $26.7 \%$ (4/ $15)$ for chemotherapy, $50.0 \%(7 / 14)$ for targeted therapy, and $89.7 \%$ (35/39) for targeted therapy combined with radiotherapy. Among those who received targeted therapy, gefitinib was used in 20 patients, erlotinib was used in 25 patients, and icotinib was used in 8 patients.

\section{Follow-up and survival}

All patients only had BMs when they entered this study. Subsequently, among all patients, as of the end of follow-up or death, a total of 61 patients had extracranial metastasis (including 36 bone metastases, 10 liver metastases, eight lung metastases, and two adrenal metastases) or malignant pleural effusions $(n=5)$. In 15 patients, local recurrence occurred (including primary foci and regional lymph nodes). The median OS was 35 months (range, 25.8-44.2 months), the one-year survival rate was $95.6 \%$, and the two-year survival rate was $74.0 \%$ (Fig. 1A). The median time to $\mathrm{BM}$ was 17 months (range, 9.620.4 months) after the initial diagnosis of NSCLC. The median mOS was 15 months, and the one-year survival rate was $51.8 \%$ (Fig. 1B). The median iPFS was 12 months (range, 7.2-16.8 months), and the rate of intracranial progression in 1 year was $48.3 \%$ (Fig. 1C).

\section{Univariable analyses}

Univariable analyses were performed to determine whether there were associations between clinical factors and mOS (Table 2). The results indicated that the ECOG score after the diagnosis of BM, the number of BMs, and the treatment after BM were associated with mOS.

Table 1 Relation between short-term response across different treatments after BMs $(n=113)$

\begin{tabular}{|c|c|c|c|c|c|c|c|}
\hline & & \multicolumn{5}{|l|}{ Response } & \multirow[t]{3}{*}{$P$} \\
\hline & & Complete & Partial & Stable & Progressive & Objective & \\
\hline Treatment & $n$ & Response & Response & Disease & Disease & $\begin{array}{l}\text { response } \\
\text { rate }\end{array}$ & \\
\hline None & 18 & 0 & 0 & $9(50.0 \%)$ & $9(50.0 \%)$ & 0 & \multirow[t]{5}{*}{$<0.05$} \\
\hline Chemotherapy & 15 & 0 & $4(26.7 \%)$ & $6(40.0 \%)$ & $5(33.3 \%)$ & $4(26.7 \%)$ & \\
\hline Radiotherapy & 27 & $5(18.5 \%)$ & $12(44.4 \%)$ & $6(22.2 \%)$ & $4(14.8 \%)$ & 17 (63.0\%) & \\
\hline Targeted & 14 & $1(7.1 \%)$ & $6(42.9 \%)$ & $5(35.7 \%)$ & $2(14.3 \%)$ & $7(50.0 \%)$ & \\
\hline Targeted combined radiotherapy & 39 & $13(33.3 \%)$ & $22(56.4 \%)$ & $3(7.7 \%)$ & $1(2.6 \%)$ & $35(89.7 \%)$ & \\
\hline
\end{tabular}



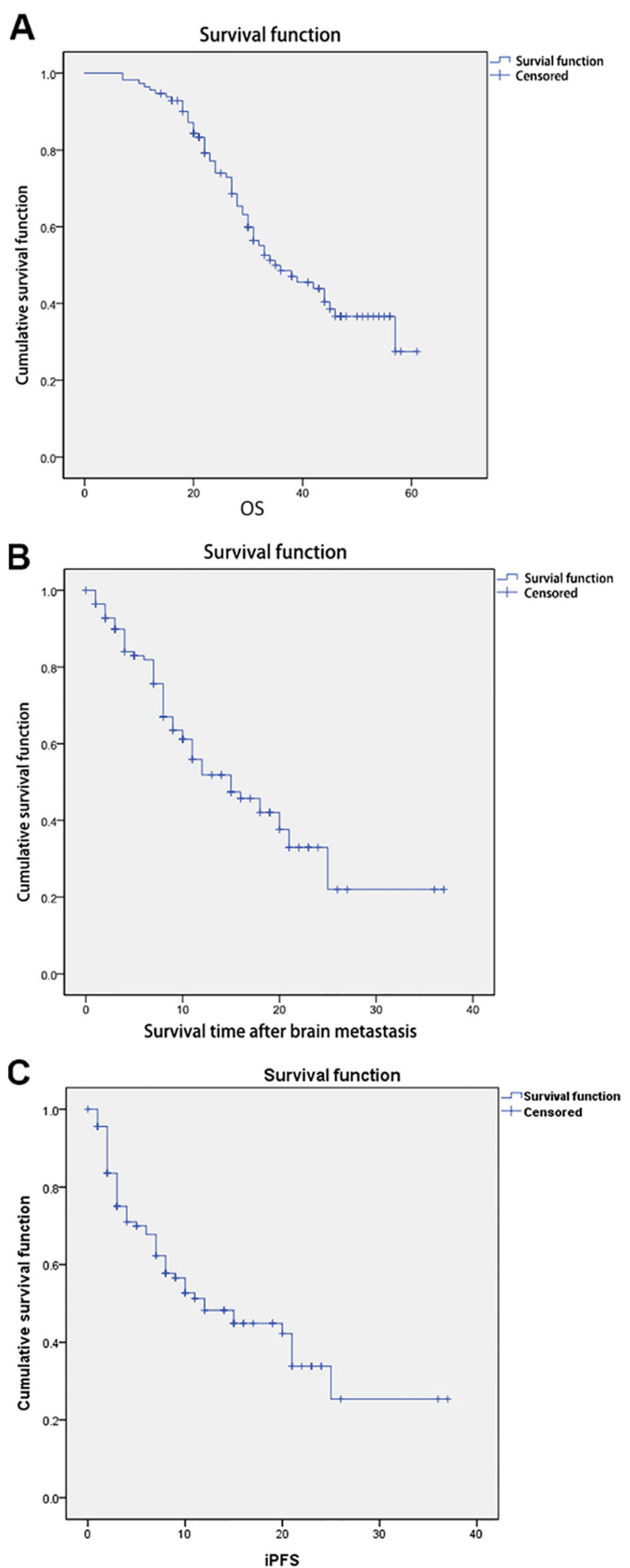

Fig. 1 Survival analysis of patients with non-small cell lung cancer (NSCLC) and brain metastases (BMs). a Overall survival (OS). b Overall survival after BM diagnosis (mOS). c intracranial progression-free survival (iPFS) 
Table 2 Univariable analyses of overall survival after BM among patients with EGFR-mutated NSCLC $(n=113)$

\begin{tabular}{|c|c|c|c|}
\hline Factors & $\mathrm{n}(\%)$ & $\mathrm{P}$ & $95 \% \mathrm{Cl}$ \\
\hline \multicolumn{4}{|l|}{ Sex } \\
\hline Male & $44(38.9 \%)$ & 0.38 & $0.47-1.34$ \\
\hline Female & $69(61.1 \%)$ & & \\
\hline \multicolumn{4}{|l|}{ Age } \\
\hline$\leq 65$ years & $91(80.5 \%)$ & 0.52 & $0.67-2.24$ \\
\hline$>65$ years & $22(19.5 \%)$ & & \\
\hline \multicolumn{4}{|l|}{ Histological type } \\
\hline Adenocarcinoma & $113(100 \%)$ & - & - \\
\hline \multicolumn{4}{|l|}{ Epidermal growth factor receptor gene mutation } \\
\hline Exon 19 & $52(46.0 \%)$ & 0.13 & $0.94-1.61$ \\
\hline Exon 21 & $61(54.0 \%)$ & & \\
\hline \multicolumn{4}{|l|}{ Number of brain metastases } \\
\hline$\leq 3$ & $57(50.3 \%)$ & $<0.01$ & $1.72-5.30$ \\
\hline$>3$ & $56(49.6 \%)$ & & \\
\hline \multicolumn{4}{|l|}{ Maximum size of brain metastases } \\
\hline$\leq 2 \mathrm{~cm}$ & $81(71.7 \%)$ & 0.33 & $0.75-2.36$ \\
\hline$>2 \mathrm{~cm}$ & $32(28.3 \%)$ & & \\
\hline \multicolumn{4}{|l|}{ Symptoms associated with brain metastasis } \\
\hline No & $67(59.3 \%)$ & 0.62 & $0.51-1.50$ \\
\hline Yes & $46(40.7)$ & & \\
\hline \multicolumn{4}{|l|}{ ECOG score } \\
\hline$\leq 2$ & $83(73.5 \%)$ & $<0.01$ & $2.84-8.11$ \\
\hline$>2$ & $30(26.5 \%)$ & & \\
\hline \multicolumn{4}{|l|}{ Treatment } \\
\hline None & $18(15.9 \%)$ & $<0.01$ & $0.55-0.86$ \\
\hline Radiotherapy & $27(23.9 \%)$ & & \\
\hline Targeted therapy in previously TKI-naïve patients & $14(12.4 \%)$ & & \\
\hline Chemotherapy & $15(13.3 \%)$ & & \\
\hline Targeted combined radiotherapy & $39(34.5 \%)$ & & \\
\hline
\end{tabular}

Abbreviation: ECOG Eastern Cooperative Oncology Group

\section{Multivariable analysis}

Cox regression analysis was used to examine the association between risk factors identified in the univariable analyses with mOS (Table 3). Three or less intracranial metastases $(P<0.001) \quad$ (Fig. 2a) and

Table 3 Multivariable analysis of the association between clinical factors and mOS in patients with NSCLC with EGFR mutation and BMs $(n=113)$

\begin{tabular}{|c|c|c|c|c|}
\hline \multirow[t]{2}{*}{ Parameters } & \multirow[t]{2}{*}{$P$} & \multirow{2}{*}{$\begin{array}{l}\text { Odds } \\
\text { ratio }\end{array}$} & \multicolumn{2}{|c|}{$95.0 \% \mathrm{Cl}$ for $\operatorname{Exp}(\mathrm{B})$} \\
\hline & & & Lower & Upper \\
\hline ECOG score & 0.080 & 1.481 & 0.953 & 2.301 \\
\hline Number of brain metastases & $<0.001$ & 3.341 & 1.890 & 5.905 \\
\hline Treatments after brain metastases & 0.001 & 0.680 & 0.543 & 0.851 \\
\hline
\end{tabular}

Abbreviations: $\mathrm{Cl}$ confidence interval, ECOG Eastern Cooperative Oncology Group treatment after $\mathrm{BM}$ diagnosis $(P=0.001)$ (Fig. 2c-d) were independently associated with better mOS, while ECOG (Fig. 2b) was not.

\section{Adverse reactions}

Of all the patients, no grade 4-5 adverse reactions occurred. Of the group of patients with targeted therapy combined radiotherapy, no intolerable side effects leading to treatment discontinuation occurred. For chemotherapy, the most common adverse reaction was weakness. For radiotherapy, the most common adverse reaction was also weakness. For targeted therapy, the most common adverse reaction was rash. For targeted therapy combined with radiotherapy, the most common adverse reaction was weakness (Table 4). 


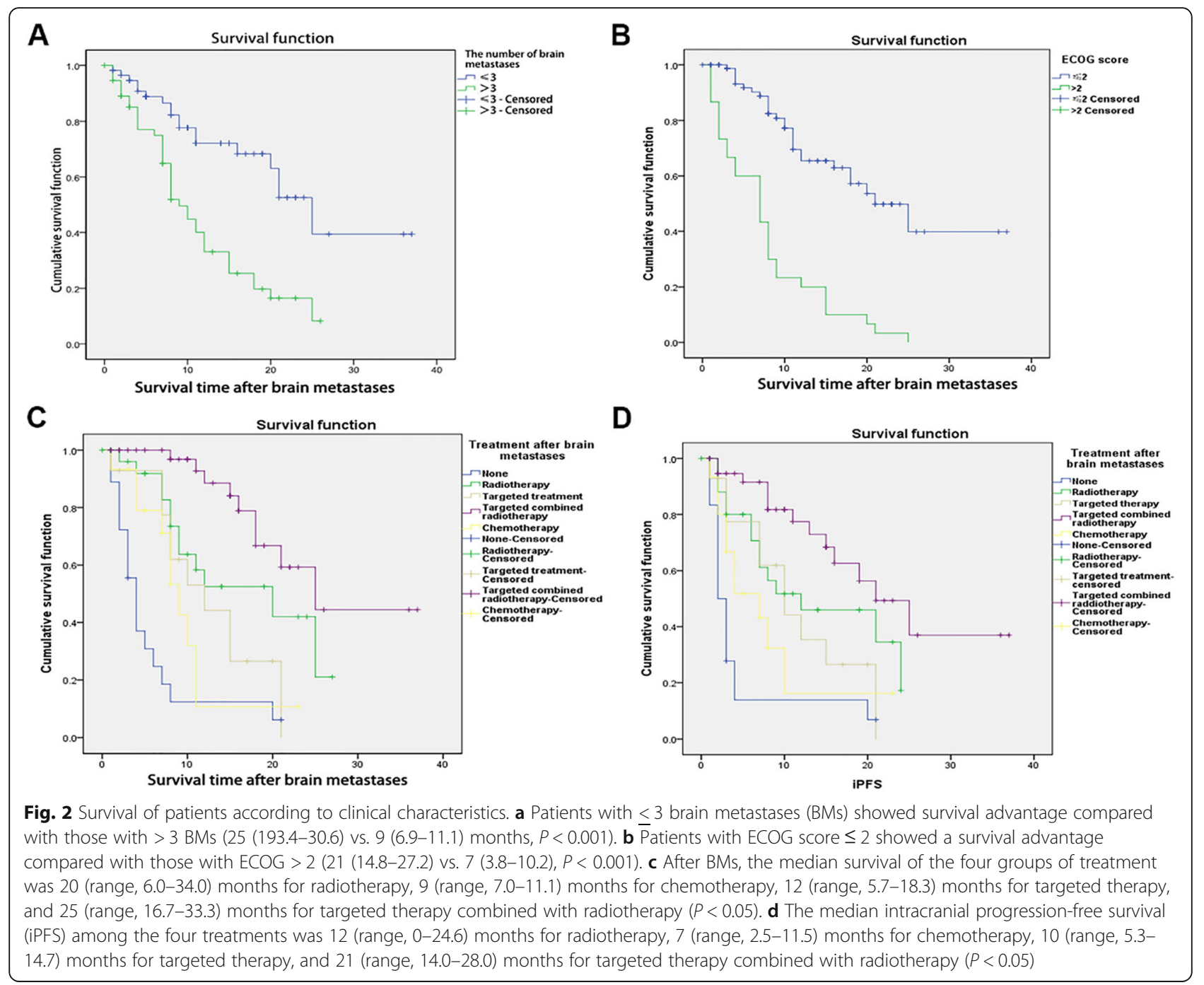

\section{Discussion}

Many patients with lung cancer develop BMs, which impacts the quality of life and shortens survival. Despite therapy, the prognosis of NSCLC patients with BMs is poor, and the 1-year survival rate is $<20 \%$ [12]. Previous studies found a significant association between EGFR mutations and the risk of $\mathrm{BM}[13,14]$ and pointed out the distinct clinical features of EGFR-mutated tumors in terms of BM [15-18]. Therefore, it is speculated that BMs in these patients exhibit their own characteristics in occurrence, treatment, and prognosis. In 1997, the RTOG put forward the recursive partitioning analysis classification for the prognosis of BMs, but this system does not take into account the epidermal growth factor receptor $(E G F R)$ mutations present. Accordingly, this study aimed to summarize the factors affecting the prognosis of these patients with EGFR-mutated lung adenocarcinoma after BM. Furthermore, this study explored the optimal treatment for these patients.
Our results indicated that the number of BMs and treatment after BM were associated with overall survival after BMs. Previous studies concluded that the performance status [6,19-21], age [6,19-21], extracranial metastases $[6,19-21]$, and primary tumor control $[19,20]$ affected survival. Other studies [12, 22, 23] indicated that the number of BMs influenced survival. The choice of treatment should be based on the current guidelines and tailored to the clinical reality of each patient. Better physical strength generally means better tolerance. Nevertheless, our results were different from previous studies, probably because previous studies did not target patients with NSCLC harboring EGFR mutation and BMs. Few studies discussed the treatment factors influencing the prognosis of patients with BM and EGFR mutation. Gong et al [24]. indicated that the number of chemotherapy cycles and combined targeted therapy was key prognostic factors influencing survival. Our results indicate that the treatments after BM were associated 
Table 4 Toxicity grading of different treatments after BMs, n (\%)

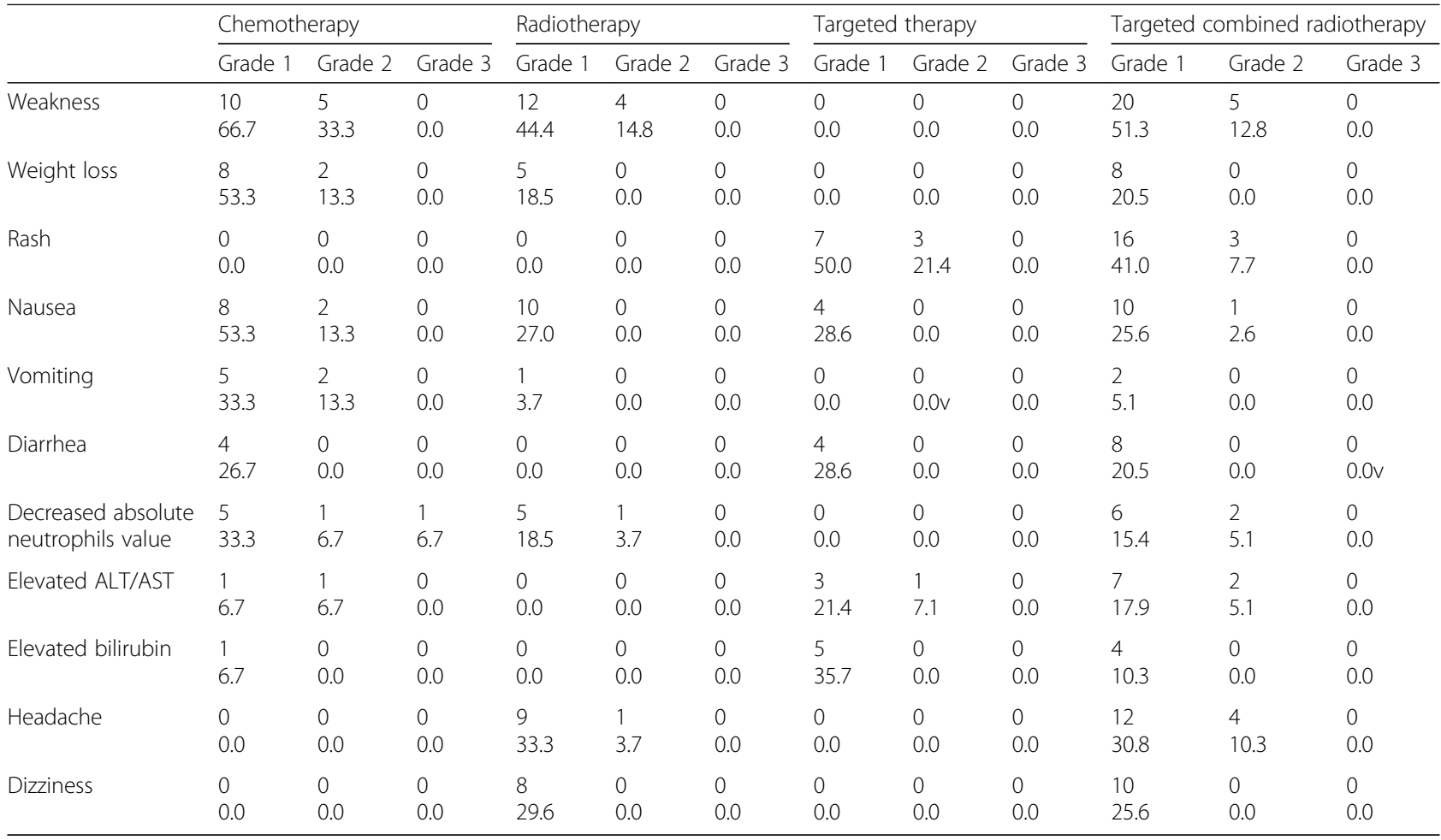

with mOS. Due to the relatively small number of patients in each group, we were unable to exhaustively assess the factors that were correlated with the prognosis of patients with BM.

The first-generation EGFR-TKIs available in China during the study period included gefitinib, erlotinib, and icotinib. The CTONG0901 study compared the PFS and OS of gefitinib and erlotinib and found that the two were equivalent [25]. The ICOGEN study was a randomized, controlled phase III clinical trial comparing gefitinib to icotinib in previously treated patients with locally advanced or metastatic non-small cell lung cancer. The results showed that there was no significant difference in PFS and OS between gefitinib and icotinib [26]. The WJOG5108L clinical trial also showed that gefitinib and erlotinib were equivalent in PFS [27]. In clinical practice, which TKI a patient chooses is related to the patient's choice and the doctor's prescription habits. In the present study, gefitinib was used in 20 patients, erlotinib was used in 25 patients, and icotinib was used in 8 patients. Due to the price advantage of icotinib, some patients chose to use it. During treatment, no advantage in the efficacy of a certain drug was found, and all three drugs were not found to have grade III-IV adverse reactions.

In the present study, patients with targeted therapy combined with radiotherapy after BM had the best survival advantage. The proportion of patients with $\mathrm{CR}$ or
PR following BMs was significantly different across treatment groups. The proportion of CR + PR was $63.0 \%$ for radiotherapy, $26.7 \%$ for chemotherapy, $50.0 \%$ for targeted therapy, and $89.7 \%$ for targeted therapy combined with radiotherapy. After BM, the median survival of the four treatment groups was $20,9,12$, and 25 months, respectively $(P<0.05)$, and their median iPFS were 12,7 , 10 , and 21 months, respectively. The prognosis of chemotherapy was the worst, similar to a previous report [28]. This is thought to be due to several factors, including the blood-brain barrier (BBB) and the inherent chemotherapy resistance of BM. Thus, WBRT has been used as a standard treatment in NSCLC patients with $\mathrm{BM}$, resulting in an OS ranging between 3 and 6 months since the 1970s [29, 30].

TKIs are small molecules and have a good lipid-water partition coefficient. They are easily absorbed and cross the BBB. Brain metastases can damage the BBB to some extent [31]. More recently, TKI therapy for BM patients with EGFR mutations achieved effective rates of $70-80 \%$ [32] and $87.8 \%$ [33]. Furthermore, the iPFS was 14.5 months, and the OS was 21.9 months. Nearly half of the patients delayed radiation therapy for more than 1.5 years after the diagnosis of BMs by using TKI [33]. Accordingly, some experts pointed out that TKI was becoming a favorable treatment, especially for patients with EGFR mutation of BMs of lung cancer. In the present study, the radiotherapy group did show some 
advantages over the targeted treatment group, probably because most patients had no more than three BMs whose maximum diameter $\leq 2 \mathrm{~cm}$, and they accepted stereotactic radiotherapy. Omuro et al. [34] and Park et al. [32] also drew similar conclusions, pointing out that TKI therapy for NSCLC brain metastases leads to a high intracranial recurrence rate and short PFS. The retrospective analysis by Magnuson et al. [35] showed that radiotherapy, compared with TKI treatment, contributed to a longer survival (34.1 vs. 19.4 months). PET/ CT images with ${ }^{11} \mathrm{C}$-erlotinib as the tracer combined with the MRI images show a significant concentration of ${ }^{11} \mathrm{C}$-erlotinib in the brain metastases, but no ${ }^{11} \mathrm{C}$-erlotinib could be found in the normal brain tissues [36]. In mouse models, compared with other EGFR-TKIs, osimertinib reaches a higher concentration in the brain and is easier to accumulate in the brain [37]. In eight healthy adult volunteers (52 \pm 8 years old), PET-CT was used to observe the distribution of ${ }^{11} \mathrm{C}$-osimertinib in the brain after a single intravenous injection of $1.2 \mu \mathrm{g}(1.1-1.4 \mu \mathrm{g})$ over $90 \mathrm{~min}$. It was found that ${ }^{11} \mathrm{C}$-osimertinib could distribute rapidly in the brain, with an average Tmax of 13 min and a brain/plasma $\mathrm{AUC}_{0-90}$ min ratio of $8.3 \pm 0.3$ [38]. In the AURA3 study, the ORR of the central nervous system was $70 \%$ in the $80-\mathrm{mg}$ osimertinib group and $31 \%$ in the platinum-containing dual drug chemotherapy group [39]. The ASTRIS open-label, real-world, international single-arm treatment study aimed to explore the efficacy and safety of osimertinib in T790Mpositive advanced NSCLC adult patients with EGFR-TKI treatment history. The results showed that for advanced NSCLC patients with the T790M mutation and asymptomatic stable CNS metastasis treated with osimertinib, the overall ORR of T790M positive was $55 \%$ and the median PFS was 9.7 months [40]. Therefore, osimertinib could have particular benefits for patients with NSCLC and brain metastases. The role of radiotherapy in the treatment of BMs still requires additional studies, and its timing in relation to different TKIs requires additional study. Nevertheless, some studies suggested that upfront TKI and radiotherapy achieved better survival than TKI alone in patients with BMs from NSCLC [41-43].

TKIs have a radio-sensitizing effect [44, 45], and radiotherapy can disrupt the BBB to improve TKI levels in the intracranial space, and this mechanism provides a theoretical basis for the idea of targeted treatment combined with radiotherapy [46]. Zeng et al. [47], Cai et al. [48], and Welsh et al. [49] supported the hypothesis that TKI combined with WBRT is more effective for the control of intracranial lesions and prolonging the survival than either therapy alone. The benefits seemed exceptionally high for patients with EGFR mutation rates. Taken together, the present provides a comprehensive comparison of the various treatments. Larger prospective randomized clinical trials are needed to validate our findings and confirm these suppositions.

\section{Strengths and limitations}

Because few of the published prognostic classification models have involved patients with EGFR mutationpositive NSCLC and brain metastases, the present study targeted this group of patients, trying to find out the factors affecting the prognosis and a better way treatment. In addition, the study made an overall comparison among the therapeutic effect of different treatments after $\mathrm{BM}$ diagnosis.

Nevertheless, there are limitations to this study. First, this study is a retrospective analysis with a relatively small number of cases and a limited follow-up duration. Second, previous studies reported that about $20-30 \%$ of patients with EGFR mutations are smokers [2, 3, 50, 51], compared with $37.2 \%$ in this article. This discrepancy might be related to the fact that this was a retrospective study with all the inherent biases, and that the number of cases is limited. Third, we included patients with parenchymal BMs but did not examine the exact nature of the extracranial lesions or the control of chest lesions. Fourth, the study factors are limited to general clinical factors and therapeutic factors. The exact dose and duration of treatment were not taken into account. Fifth, individualized hematology indexes and molecular indicators were not assessed. Finally, a large number of variables were included in the multivariable analysis and could make the associations inaccurate because of the small number of patients [52]. The present study should be seen as a preliminary study that tried to identify factors that could be associated with survival in a very selected population of patients, but those factors cannot be used directly to manage patients and need to be confirmed. Therefore, this study cannot provide a comprehensive reflection of the emergence, development, and prognosis of BMs in those patients. Improved data collection and/or a randomized controlled study are necessary to further examine these questions.

\section{Conclusions}

In conclusion, the prognosis of the patients with NSCLC harboring EGFR mutation and BMs may be related to the number of metastatic brain lesions and the treatment methods of BMs. TKI, combined with radiotherapy, may have some advantages over other treatments in those patients. Larger prospective randomized clinical trials are needed to validate our findings and confirm these results.

\section{Abbreviations}

RTOG: Radiation Therapy Oncology Group; BMs: Brain metastases; EGFR: Epidermal growth factor receptor; NSCLC: Non-small cell lung cancer; TKI: Tyrosine kinase inhibitor; OS: Overall survival; iPFS: Intracranial 
progression-free survival; Cl: Confidence interval; RPA: Recursive partitioning analysis; WBRT: Whole-brain radiotherapy; SRS: Stereotactic radiosurgery; MRI: Magnetic resonance; CR: Complete response; PR: Partial response; SD: Stable disease; PD: Progressive disease; ORR: Objective response rate; CTCAE: Common Terminology Criteria for Adverse Events; BBB: Blood-brain barrier

\section{Acknowledgments}

Not applicable.

\section{Authors' contributions}

JW1, ZYL, PW, and JW2 carried out the studies, participated in collecting data, and drafted the manuscript. PCE and YWW performed the statistical analysis and participated in its design. QSP, TZ, and XC helped to draft the manuscript. All authors read and approved the final manuscript.

\section{Funding}

None.

\section{Availability of data and materials}

The datasets used and analyzed during the current study are available from the corresponding author on reasonable request.

\section{Ethics approval and consent to participate}

The study was carried out in accordance with the Declaration of Helsinki and was approved by the ethics committee of Tianjin Medical University Cancer Institute \& Hospital. The need for individual consent was waived by the committee.

\section{Consent for publication}

Not applicable.

\section{Competing interests}

The authors declare that they have no competing interests.

Received: 2 October 2019 Accepted: 3 August 2020

Published online: 03 September 2020

\section{References}

1. Siegel RL, Miller KD, Jemal A. Cancer statistics, 2019. CA Cancer J Clin. 2019; 69:7-34.

2. NCCN. Clinical practice guidelines in oncology (NCCN guidelines). Non-small cell lung Cancer. Version 4.2019. Fort Washington: National Comprehensive Cancer Network; 2019.

3. Novello S, Barlesi F, Califano R, Cufer T, Ekman S, Levra MG, et al. Metastatic non-small-cell lung cancer: ESMO clinical practice guidelines for diagnosis, treatment and follow-up. Ann Oncol. 2016;27:v1-v27.

4. Cao M, Chen W. Epidemiology of lung cancer in China. Thorac Cancer. 2019;10:3-7.

5. Soria JC, Ohe Y, Vansteenkiste J, Reungwetwattana T, Chewaskulyong B, Lee $\mathrm{KH}$, et al. Osimertinib in untreated EGFR-mutated advanced non-small-cell lung Cancer. N Engl J Med. 2018;378:113-25.

6. Gaspar L, Scott C, Rotman M, Asbell S, Phillips T, Wasserman T, et al. Recursive partitioning analysis (RPA) of prognostic factors in three radiation therapy oncology group (RTOG) brain metastases trials. Int J Radiat Oncol Biol Phys. 1997;37:745-51.

7. Lu Y, Fan Y. Combined action of EGFR tyrosine kinase inhibitors and wholebrain radiotherapy on EGFR-mutated non-small-cell lung cancer patients with brain metastasis. Onco Targets Ther. 2016;9:1135-43.

8. Soffietti R, Chiavazza C, Ruda R. Imaging and clinical end points in brain metastases trials. CNS Oncol. 2017;6:243-6.

9. Suteu P, Fekete Z, Todor N, Nagy V. Survival and quality of life after whole brain radiotherapy with 3D conformal boost in the treatment of brain metastases. Med Pharm Rep. 2019;92:43-51.

10. Schwartz LH, Litiere S, de Vries E, Ford R, Gwyther S, Mandrekar S, et al. RECIST 1.1-update and clarification: from the RECIST committee. Eur J Cancer. 2016:62:132-7.

11. Trotti A, Colevas AD, Setser A, Rusch V, Jaques D, Budach V, et al. CTCAE v3. 0 : development of a comprehensive grading system for the adverse effects of cancer treatment. Semin Radiat Oncol. 2003;13:176-81.
12. Sperduto PW, Kased N, Roberge D, Xu Z, Shanley R, Luo X, et al. Summary report on the graded prognostic assessment: an accurate and facile diagnosis-specific tool to estimate survival for patients with brain metastases. J Clin Oncol. 2012;30:419-25.

13. Shin DY, Na II, Kim CH, Park S, Baek H, Yang SH. EGFR mutation and brain metastasis in pulmonary adenocarcinomas. J Thorac Oncol. 2014:9:195-9.

14. Lee YJ, Park IK, Park MS, Choi HJ, Cho BC, Chung KY, et al. Activating mutations within the EGFR kinase domain: a molecular predictor of diseasefree survival in resected pulmonary adenocarcinoma. J Cancer Res Clin Oncol. 2009;135:1647-54.

15. Iuchi T, Shingyoji M, Itakura M, Yokoi S, Moriya $Y$, Tamura $H$, et al. Frequency of brain metastases in non-small-cell lung cancer, and their association with epidermal growth factor receptor mutations. Int J Clin Oncol. 2015;20:674-9.

16. Heon S, Yeap BY, Britt GJ, Costa DB, Rabin MS, Jackman DM, et al. Development of central nervous system metastases in patients with advanced non-small cell lung cancer and somatic EGFR mutations treated with gefitinib or erlotinib. Clin Cancer Res. 2010;16:5873-82.

17. Eichler AF, Kahle KT, Wang DL, Joshi VA, Willers H, Engelman JA, et al. EGFR mutation status and survival after diagnosis of brain metastasis in nonsmall cell lung cancer. Neuro-Oncology. 2010;12:1193-9.

18. Enomoto $Y$, Takada K, Hagiwara E, Kojima E. Distinct features of distant metastasis and lymph node stage in lung adenocarcinoma patients with epidermal growth factor receptor gene mutations. Respir Investig. 2013;51: 153-7.

19. Gerosa M, Nicolato A, Foroni R, Tomazzoli L, Bricolo A. Analysis of long-term outcomes and prognostic factors in patients with non-small cell lung cancer brain metastases treated by gamma knife radiosurgery. J Neurosurg. 2005;102(Suppl):75-80.

20. Zindler JD, Rodrigues G, Haasbeek CJ, De Haan PF, Meijer OW, Slotman BJ, et al. The clinical utility of prognostic scoring systems in patients with brain metastases treated with radiosurgery. Radiother Oncol. 2013;106:370-4.

21. Rades D, Schild SE, Lohynska R, Veninga T, Stalpers LJ, Dunst J. Two radiation regimens and prognostic factors for brain metastases in nonsmall cell lung cancer patients. Cancer. 2007;110:1077-82.

22. Sperduto PW, Berkey B, Gaspar LE, Mehta M, Curran W. A new prognostic index and comparison to three other indices for patients with brain metastases: an analysis of 1,960 patients in the RTOG database. Int J Radiat Oncol Biol Phys. 2008;70:510-4.

23. Rotin DL, Paklina OV, Kobiakov GL, Shishkina LV, Kravchenko EV, Stepanian MA. Lung cancer metastases to the brain: clinical and morphological prognostic factors. Zh Vopr Neirokhir Im N N Burdenko. 2013;77:24-8 discussion 9.

24. Gong X, Zhou D, Liang S, Zhou C. Analyses of prognostic factors in cases of non-small cell lung cancer with multiple brain metastases. Onco Targets Ther. 2016:9:977-83.

25. Yang JJ, Zhou Q, Yan HH, Zhang XC, Chen HJ, Tu HY, et al. A phase II randomised controlled trial of erlotinib vs gefitinib in advanced non-small cell lung cancer with EGFR mutations. Br J Cancer. 2017;116:568-74.

26. Shi $Y$, Zhang L, Liu X, Zhou C, Zhang L, Zhang S, et al. Icotinib versus gefitinib in previously treated advanced non-small-cell lung cancer (ICOGEN): a randomised, double-blind phase 3 non-inferiority trial. Lancet Oncol. 2013;14:953-61

27. Urata Y, Katakami N, Morita S, Kaji R, Yoshioka H, Seto T, et al. Randomized phase III study comparing Gefitinib with Erlotinib in patients with previously treated advanced lung adenocarcinoma: WJOG 5108L. J Clin Oncol. 2016;34: 3248-57.

28. Zimmermann S, Dziadziuszko R, Peters S. Indications and limitations of chemotherapy and targeted agents in non-small cell lung cancer brain metastases. Cancer Treat Rev. 2014;40:716-22.

29. Diener-West M, Dobbins TW, Phillips TL, Nelson DF. Identification of an optimal subgroup for treatment evaluation of patients with brain metastases using RTOG study 7916. Int J Radiat Oncol Biol Phys. 1989;16:669-73.

30. Borgelt B, Gelber R, Kramer S, Brady LW, Chang CH, Davis LW, et al. The palliation of brain metastases: final results of the first two studies by the radiation therapy oncology group. Int J Radiat Oncol Biol Phys. 1980;6:1-9.

31. Jamal-Hanjani M, Spicer J. Epidermal growth factor receptor tyrosine kinase inhibitors in the treatment of epidermal growth factor receptor-mutant non-small cell lung cancer metastatic to the brain. Clin Cancer Res. 2012;18: 938-44.

32. Park SJ, Kim HT, Lee DH, Kim KP, Kim SW, Suh C, et al. Efficacy of epidermal growth factor receptor tyrosine kinase inhibitors for brain metastasis in non- 
small cell lung cancer patients harboring either exon 19 or 21 mutation. Lung Cancer. 2012;77:556-60.

33. Iuchi T, Shingyoji M, Sakaida T, Hatano K, Nagano O, Itakura M, et al. Phase II trial of gefitinib alone without radiation therapy for Japanese patients with brain metastases from EGFR-mutant lung adenocarcinoma. Lung Cancer. 2013;82:282-7

34. Omuro AM, Kris MG, Miller VA, Franceschi E, Shah N, Milton DT, et al. High incidence of disease recurrence in the brain and leptomeninges in patients with nonsmall cell lung carcinoma after response to gefitinib. Cancer. 2005; 103:2344-8.

35. Magnuson WJ, Yeung JT, Guillod PD, Gettinger SN, Yu JB, Chiang VL. Impact of deferring radiation therapy in patients with epidermal growth factor receptor-mutant non-small cell lung Cancer who develop brain metastases. Int J Radiat Oncol Biol Phys. 2016;95:673-9.

36. Weber B, Winterdahl M, Memon A, Sorensen BS, Keiding S, Sorensen L, et al. Erlotinib accumulation in brain metastases from non-small cell lung cancer: visualization by positron emission tomography in a patient harboring a mutation in the epidermal growth factor receptor. J Thorac Oncol. 2011;6: $1287-9$.

37. Ballard P, Yates JW, Yang Z, Kim DW, Yang JC, Cantarini M, et al. Preclinical comparison of Osimertinib with other EGFR-TKIs in EGFR-mutant NSCLC brain metastases models, and early evidence of clinical brain metastases activity. Clin Cancer Res. 2016;22:5130-40.

38. Vishwanathan K, Varrone A, Varnas K. Abstract CT013: Osimertinib displays high brain exposure in healthy subjects with intact blood-brain barrier: a microdose positron emission tomography (PET) study with 11C-labelled osimertinib. Cancer Res:7482018.

39. Mok TS, Wu YL, Ahn MJ, Garassino MC, Kim HR, Ramalingam SS, et al. Osimertinib or platinum-Pemetrexed in EGFR T790M-positive lung Cancer. N Engl J Med. 2017;376:629-40

40. Metro G, Provencio M, Kim DW. 1521P - Osimertinib in epidermal growth factor receptor (EGFR) T790M advanced non-small cell lung cancer (NSCLC): analysis of patients with central nervous system (CNS) metastases in a realworld study (ASTRIS). Ann Oncol. 2019;30:v624.

41. Wang C, Lu X, Lyu Z, Bi N, Wang L. Comparison of up-front radiotherapy and TKI with TKI alone for NSCLC with brain metastases and EGFR mutation: a meta-analysis. Lung Cancer. 2018;122:94-9.

42. Chen Y, Wei J, Cai J, Liu A. Combination therapy of brain radiotherapy and EGFR-TKIs is more effective than TKIs alone for EGFR-mutant lung adenocarcinoma patients with asymptomatic brain metastasis. BMC Cancer. 2019;19:793.

43. Dong $\mathrm{K}$, Liang W, Zhao S, Guo M, He Q, Li C, et al. EGFR-TKI plus brain radiotherapy versus EGFR-TKI alone in the management of EGFR-mutated NSCLC patients with brain metastases. Transl Lung Cancer Res. 2019;8:26879.

44. Zhuang HQ, Sun J, Yuan ZY, Wang J, Zhao LJ, Wang P, et al. Radiosensitizing effects of gefitinib at different administration times in vitro. Cancer Sci. 2009;100:1520-5.

45. Halatsch ME, Low S, Mursch K, Hielscher T, Schmidt U, Unterberg A, et al. Candidate genes for sensitivity and resistance of human glioblastoma multiforme cell lines to erlotinib. Laboratory investigation. J Neurosurg. 2009;111:211-8.

46. Zhuang $\mathrm{H}$, Wang J, Zhao L, Yuan Z, Wang P. The theoretical foundation and research progress for WBRT combined with erlotinib for the treatment of multiple brain metastases in patients with lung adenocarcinoma. Int J Cancer. 2013;133:2277-83.

47. Zeng YD, Zhang L, Liao H, Liang Y, Xu F, Liu JL, et al. Gefitinib alone or with concomitant whole brain radiotherapy for patients with brain metastasis from non-small-cell lung cancer: a retrospective study. Asian Pac J Cancer Prev. 2012;13:909-14.

48. Cai L, Zhu JF, Zhang XW, Lin SX, Su XD, Lin P, et al. A comparative analysis of EGFR mutation status in association with the efficacy of TKI in combination with WBRT/SRS/surgery plus chemotherapy in brain metastasis from non-small cell lung cancer. J Neuro-Oncol. 2014;120:423-30.

49. Welsh JW, Komaki R, Amini A, Munsell MF, Unger W, Allen PK, et al. Phase II trial of erlotinib plus concurrent whole-brain radiation therapy for patients with brain metastases from non-small-cell lung cancer. J Clin Oncol. 2013; 31:895-902.

50. Hasegawa Y, Ando M, Maemondo M, Yamamoto S, Isa S, Saka H, et al. The role of smoking status on the progression-free survival of non-small cell lung cancer patients harboring activating epidermal growth factor receptor
(EGFR) mutations receiving first-line EGFR tyrosine kinase inhibitor versus platinum doublet chemotherapy: a meta-analysis of prospective randomized trials. Oncologist. 2015;20:307-15.

51. D'Angelo SP, Pietanza MC, Johnson ML, Riely GJ, Miller VA, Sima CS, et al, Incidence of EGFR exon 19 deletions and L858R in tumor specimens from men and cigarette smokers with lung adenocarcinomas. J Clin Oncol. 2011; 29:2066-70.

52. Peduzzi P, Concato J, Kemper E, Holford TR, Feinstein AR. A simulation study of the number of events per variable in logistic regression analysis. J Clin Epidemiol. 1996;49:1373-9.

\section{Publisher's Note}

Springer Nature remains neutral with regard to jurisdictional claims in published maps and institutional affiliations.
Ready to submit your research? Choose BMC and benefit from:

- fast, convenient online submission

- thorough peer review by experienced researchers in your field

- rapid publication on acceptance

- support for research data, including large and complex data types

- gold Open Access which fosters wider collaboration and increased citations

- maximum visibility for your research: over $100 \mathrm{M}$ website views per year

At BMC, research is always in progress.

Learn more biomedcentral.com/submissions 